\title{
Percepção das gestantes adolescentes sobre as consultas de pré-natal em um hospital
} escola

\author{
Perception of pregnant teenagers about prenatal consultations at a teaching hospital \\ Percepción de las adolescentes embarazadas sobre las consultas prenatales em um hospital \\ universitario
}

Recebido: 06/04/2021 | Revisado: 13/04/2021 | Aceito: 19/04/2021 | Publicado: 05/05/2021

\author{
Marcela Claudia de Paula Oliveira \\ ORCID: https://orcid.org/0000-0002-7762-0684 \\ Universidade de Pernambuco, Brasil \\ E-mail: marcela-claudia2011@hotmail.com \\ Fátima Maria França Trindade \\ ORCID: https://orcid.org/0000-0002-0548-6682 \\ Universidade Federal de Pernambuco, Brasil \\ E-mail: fatimamftrindade@gmail.com \\ Cinthia Martins Menino Diniz \\ ORCID: https://orcid.org/0000-0001-5405-9057 \\ Universidade Federal de Pernambuco, Brasil \\ E-mail: cinthianesto@gmail.com \\ Kelita Mirelle Oliveira Lima \\ ORCID: https://orcid.org/0000-0002-3783-2201 \\ Universidade Federal de Pernambuco, Brasil \\ E-mail: kelita_mirelle_sp@hotmail.com \\ Maria Glecia Saraiva Lettieri \\ ORCID: https://orcid.org/0000-0001-7949-491X \\ Universidade Federal de Pernambuco, Brasil \\ E-mail: diletieri26@hotmail.com \\ Tássia Daniele Lima Almeida \\ ORCID: https://orcid.org/0000-0002-7164-8096 \\ Universidade Federal de Pernambuco, Brasil \\ E-mail: tassia.daniele@ hotmail.com
}

\begin{abstract}
Resumo
Teve como objetivo identificar a percepção das gestantes adolescentes sobre as consultas de pré-natal em um hospital escola. Estudo descritivo, exploratório, com abordagem qualitativa, realizado no ambulatório de pré-natal de um Hospital Universitário na Cidade do Recife-PE, e aprovado pelo Comitê e Ética e Pesquisa do local de estudo. Foram incluídas gestantes com idade entre 10-19 anos, onde a Organização Mundial da Saúde circunscreve a adolescência à segunda década da vida (de 10 a 19 anos), com pelo menos três consultas de pré-natal e excluídas as que mesmo após todas as explicações, não compreenderam o objetivo da pesquisa. Participaram da pesquisa cinco gestantes do prénatal médico, com idades entre 12 e 19 anos. A maioria eram solteiras $(n=05)$, cinco ainda estudam, uma possuía ensino médio completo e outra o ensino fundamental. 04 moram em Recife e todas residem em área urbana. A maioria ( $n=05)$ se considera da cor parda, 05 possuíam renda familiar até um salário mínimo, duas mais que um salário e nenhuma trabalhava. Do processo de análise do discurso das participantes emergiram dois eixos temáticos: atendimento nas consultas de pré-natal: visão das gestantes e educação em saúde nas consultas de pré-natal. O presente estudo possibilitou conhecer como ocorrem as consultas médicas de pré-natal e como as gestantes adolescentes percebem a educação em saúde.
\end{abstract}

Palavras-chave: Gravidez; Adolescência; Pré-natal.

\begin{abstract}
Had as to identify the perception of pregnant adolescents about prenatal consultations in a teaching hospital. Descriptive, exploratory study with a qualitative approach, carried out in the prenatal outpatient clinic of a University Hospital in the City of Recife-PE and approved by the Ethics and Research Committee the place of study. Pregnant women aged 10-19 years, where the World Health Organization circumscribes adolescence to the second decade of life (10 to 19 years old), with at least three prenatal consultations were included and excluded those who, even after all the explanations, did not understand the objective of the research. Five pregnant women from 12 to 19 years of age participated in the research. Most were single $(n=05)$, five are still studying, one had completed high school and the other had elementary school. 04 live in Recife and all live in an urban area. Most $(n=05)$ consider themselves to be
\end{abstract}


brown, 05 had family income up to a minimum wage, two more than one salary and none worked. From the process of analyzing the participants' discourse, two thematic axes emerged: care in prenatal consultations: view of pregnant women and health education in prenatal consultations. The present study made it possible to know how prenatal medical consultations take place and how pregnant adolescents perceive health education.

Keywords: Pregnancy; Adolescence; Prenatal.

\section{Resumen}

Tuvo como objetivo identificar la percepción de las adolescentes embarazadas sobre las consultas prenatales en un hospital universitario. Estudio descriptivo, exploratorio con abordaje cualitativo, realizado en el ambulatorio prenatal de un Hospital Universitario de la ciudad de Recife-PE, y aprobado por el Comité de Ética e Investigación del lugar de estudio. Se incluyeron mujeres embarazadas de 10 a 19 años, donde la Organización Mundial de la Salud circunscribe la adolescencia a la segunda década de la vida (10 a 19 años), con al menos tres consultas prenatales y se excluyeron aquellas que, aún después de todas las explicaciones, no entendieron el objetivo de la investigación. En la investigación participaron cinco mujeres embarazadas del período médico prenatal, con edades comprendidas entre los 12 y los 19 años. La mayoría eran solteros $(\mathrm{n}=05)$, cinco siguen estudiando, uno había terminado la escuela secundaria y el otro tenía la escuela primaria. 04 viven en Recife y todos viven en una zona urbana. La mayoría ( $\mathrm{n}=$ 05) se consideraba morena, 05 tenía un ingreso familiar de hasta un salario mínimo, dos más de un salario y ninguno trabajaba. Del proceso de análisis del discurso de las participantes surgieron dos ejes temáticos: la atención en las consultas prenatales: visión de la gestante y la educación para la salud en las consultas prenatales. El presente estudio permitió comprender cómo se realizan las consultas médicas prenatales y cómo perciben la educación para la salud las adolescentes embarazadas.

Palabras clave: Embarazo; Adolescencia; Prenatal.

\section{Introdução}

A adolescência é uma etapa da vida entre a infância e a fase adulta, período em que ocorre uma série de modificações no desenvolvimento biopsicossocial, que muitas vezes coincide com o início da vida social (Brasil, 2017). O Ministério da Saúde (2017) segue a definição da Organização Mundial de Saúde (OMS), que caracteriza essa fase na faixa etária entre 10 e 19 anos de idade (Brasil, 2018). A sexualidade é inevitável, sendo na adolescência que começa a ser vivenciada com mais intensidade e cada vez mais cedo; iniciando a vida sexual, entre 12 e 17 anos de idade, 15 anos em média, fator que pode desencadear uma gravidez precoce (Araujo et al. 2016; Brasil, 2018; Habito et al. 2019; Loll et al. 2019).

Estima-se que, mundialmente, haja 46 nascimentos para cada mil meninas com idade entre 15 e 19 anos, por ano. No Brasil esse percentual chega a 68,4 o que o deixa acima da média latino-americana que é de 65,5 (Brasil, 2018). Cerca de 25\% de 1,1 milhão de adolescentes parturientes entre 15 e 19 anos já possuem um filho (Rodrigues et al. 2016).

As regiões brasileiras, Norte $(22,31 \%)$ e Nordeste $(18,92 \%)$, contam com o maior número de gestantes adolescentes grávidas com idades entre 15 e 19 anos. No estado de Pernambuco, em 2017, 18,54\% dos nascidos vivos eram dessa faixa etária o deixando com a média bem próxima da região compreendida pelo mesmo, indicando um alto índice de ocorrência (SINASC, 2018).

A gravidez no período da adolescência é um episódio de grande relevância social, por muitas vezes serem não planejadas, indesejada ou até mesmo ocorrida pela falta de informação sobre sexualidade, da mesma forma que, não pode ser desassociada das incitações pessoais da predileção dessa adolescente em ser mãe (Araujo et al. 2016; Rodrigues et al. 2016). Essa condição é responsável pela principal causa de morte entre meninas de 15 a 19 anos em todo o mundo, o risco de morte duplica quando a mãe tem menos de 15 anos (Rosa, 2018; Leal et al. 2019).

Quando ocorre associada à dificuldade de acesso a saúde, a falta de informação, educação sexual e autonomia por parte dos adolescentes, favorece a interrupção por práticas de aborto em condições precárias, culminado, muitas vezes em hemorragias, infecção ou perfuração uterina (Brandão et al. 2017; Tomasi et al. 2017; Loll et al. 2019). Além disso, o risco aumentado de prematuridade, baixo peso ao nascer, aborto natural, pré-natal inexistente ou inadequado, dentre outras complicações, concorre para um aumento da mortalidade materna e perinatal (OPAS, 2017). 
Esse evento é um tema que deve ser discutido, por refletir a vulnerabilidade dos direitos sexuais e reprodutivos, pode levar a um grande impacto socioeconômico, resultar na interrupção de projeto de vida, abandono dos estudos ou até mesmo na dificuldade para ser conseguir um emprego (Brasil, 2017; Habito et al. 2019; Leal et al. 2019).

Tendo em vista esse problema de saúde pública, o Ministério da Saúde (2018) tem investido na criação de políticas, que visam o desenvolvimento de propostas e ações centralizadas na saúde voltadas para as adolescentes, como: o Programa de Assistência Integral à Saúde da Mulher (PAISM), Programa Saúde do Adolescente (PROSAD), Programa de Humanização no Pré-Natal e Nascimento (PHPN), a Rede Cegonha, entre outros (BRASIL, 2017; Tomasi et al. 2017; Rosa, 2018; OPAS, 2019; Nunes et al. 2016). Em Recife, o programa Hoje Menina, Amanhã Mulher, iniciativa da Secretaria da Mulher do Recife em parceria com o Unicef e o Centro das Mulheres do Cabo, tem investido na educação em saúde por meio da promoção dos direitos sexuais e reprodutivos das adolescentes incentivando o conhecimento e empoderamento dessas meninas (Rosa, 2018).

As práticas de educação em saúde são uma grande aliada de uma boa assistência nessa fase da vida. É uma estratégia capaz de construir sujeitos ativos e participantes, todos em direção a um único objetivo, o de trabalhar em conjunto para um projeto de vida libertador. Atividade que proporciona aos indivíduos autonomia na tomada de decisão através da reflexão além de assegurar o direito de escolha, dá responsabilidade na condução da sua própria história (Ramos et al. 2018).

Quando aplicadas durante as consultas de pré-natal, conduz a gestante durante todo o ciclo gravídico por meio de cuidados específicos e acolhimento humanizado, além de garantir condições de saúde adequadas, visando a redução da morbimortalidade materna e fetal (Gomes et al. 2019). Os profissionais de saúde devem promover as atividades educativas e preventivas; prezar pela qualidade, humanização, acolhimento e boa comunicação, bem como o fornecimento de diagnósticos e tratamentos apropriados das possíveis intercorrências que possam aflorar durante esse período (Matos et al. 2017; Queiroz et al. 2017).

Para isso, os enfermeiros podem utilizar de meios que facilitem essa promoção à saúde, tais como: discussões grupais, dinâmicas, dramatizações através dos grupos de gestantes ou puérperas e abordagens em sala de espera, aspirando não só um cuidado humanizado e amplo às adolescentes, mas também proporcionando o empoderamento das mesmas, bem como sua rede de apoio na gerência do seu cuidado (Matos et al. 2017). Deve-se aproveitar para abordar temas relacionados aos principais desconfortos que ocorrem durante a gestação; a importância de uma alimentação balanceada e nutritiva; o autocuidado; os benefícios do aleitamento materno exclusivo; sinais de alerta que indiquem a necessidade de procurar um serviço de saúde e sinais de trabalho de parto dentre outros (Brasil, 2018).

Visto que as consultas de pré-natal atuam como efeito protetor sobre a saúde da gestante e do recém-nascido, e contribuem para uma melhor qualidade de vida materno-infantil, esse artigo teve como objeto de estudo identificar a percepção das gestantes adolescentes sobre as consultas de pré-natal em um hospital escola conduzido pela seguinte questão norteadora: Qual a percepção das gestantes adolescentes sobre as consultas de pré-natal em um hospital escola na cidade do Recife-PE?

\section{Metodologia}

Estudo descritivo do tipo exploratório, com abordagem qualitativa, a qual atua no universo de significados, motivos, aspirações, crenças, valores e atitudes, o que equivale a um espaço mais profundo das relações, dos processos e dos fenômenos que não podem ser limitados à operacionalização de variáveis (Minayo, 2001).

O estudo foi desenvolvido no ambulatório de pré-natal de um Hospital Universitário na Cidade do Recife-PE, o qual realiza o acompanhamento de gestantes de risco habitual no pré-natal coletivo e atendimento médico para alto risco materno e fetal.

Para assegurar a ocorrência das informações pretendidas, as participantes do estudo atenderam aos seguintes critérios de inclusão: gestantes com idade entre 10-19 anos de risco habitual e ter realizado pelo menos três consultas de pré-natal no 
local do estudo; e exclusão: gestantes que mesmo após todas as explicações, não compreenderam o objetivo da pesquisa.

A amostra constituiu-se por sete gestantes, segundo critérios de saturação do conteúdo (Minayo, 2001). A coleta de dados ocorreu entre os meses de agosto a novembro de 2018. Para a realização da entrevista foi escolhido um local reservado e privativo para garantir a privacidade as gestantes para responder as perguntas. Uma vez selecionadas, as gestantes foram submetidas a uma entrevista semiestruturada composta por duas partes: a primeira com questões objetivas referentes ao perfil sociodemográfico e obstétrico das participantes; e a segunda, com questões abertas que estimulava as gestantes a expressarem suas percepções sobre as consultas de pré-natal, tendo como pergunta norteadora qual a percepção das gestantes adolescentes sobre as consultas de pré-natal em um hospital escola?

As entrevistas foram gravadas, com duração de até trinta minutos, e transcritas na íntegra com o auxilio do software Microsoft Word 2010. A análise e interpretação dos dados qualitativos foram realizadas por meio da análise do conteúdo: abordando uma fase de pré-análise e exploração dos dados, seguida da organização sistemática dos dados em categorias, com descrição detalhada das características pertinentes. Composta por três fases: a pré-análise, exploração do material e tratamento dos resultados e interpretação (Bardin, 2006).

Dessa análise surgiram as seguintes categorias temáticas: atendimento nas consultas de pré-natal e educação em saúde nas consultas de pré-natal. Após a categorização das respostas, procedeu-se, então, a inferência por meio dos dados obtidos e utilizando como base teórica o material disponível em publicações científicas acerca das consultas de pré-natal.

O desenvolvimento do estudo ocorreu em conformidade com o preconizado pela Resolução 466/2012 do Conselho Nacional de Saúde e o projeto foi aprovado pelo Comitê e Ética e Pesquisa do Hospital das Clínicas de Pernambuco (parecer 3.488.007/2019). Todas as participantes assinaram o Termo de Assentamento Livre e Esclarecido (TALE) e seus responsáveis o Termo de Consentimento Livre e Esclarecido (TCLE), ambos em duas vias.

\section{Resultados e Discussão}

\section{Categorização}

Participaram da pesquisa 05 gestantes adolescentes do pré-natal médico, com idades entre 12 e 19 anos, o que é esperado para esse grupo populacional, cuja gravidez ocorre, geralmente, entre 16 e 17 anos de idade (UNFPA, 2016). Apesar da maioria serem solteiras $(\mathrm{n}=05)$, todas estavam em relacionamento conjugal com o pai da criança. Quanto à escolaridade, cinco ainda estudam, uma possuía ensino médio completo e outra o ensino fundamental.

O Ato de estudar e concluir os estudos age como fator de proteção para gravidez precoce. A escola é considerada um excelente recurso para fins de reflexão sobre educação sexual e reprodutiva, e conta com programas de promoção à saúde que através de temas da realidade dos jovens introduz conhecimentos sobre doenças sexualmente transmissíveis, drogas, violência inclusive a gravidez (Santos et al. 2017). Através do vínculo da escola e serviço de saúde, pode ser instituída uma educação em saúde que utilize estratégias com foco nas vulnerabilidades enfrentadas por essa faixa etária, fortalecendo e ampliando a interrelação dos profissionais.

Das adolescentes entrevistadas 04 moram em Recife e todas residem em área urbana. A maioria $(\mathrm{n}=05)$ se considera da cor parda, 05 possuíam renda familiar até um salário mínimo, duas mais que um salário e nenhuma trabalhava; corroborando com dados que traz a população brasileira, em especial mulheres negras e pardas, na faixa etária até 14 anos como as que mais se encontram em nível socioeconômico baixo (IBGE, 2017).

No que se referem às características obstétricas seis das gestantes eram primigestas e uma secundigesta. A única participante que declarou ter sido mãe informou que seu filho nasceu de parto normal; e nenhuma teve aborto espontâneo ou provocado. Três estavam no segundo trimestre da gestação e quatro no terceiro trimestre, com datas prováveis do parto para final de 2019 e início de 2020. A maioria iniciou o pré-natal no primeiro trimestre (n=04) e seis compareciam corretamente as 
consultas. O Ministério da Saúde recomenda que sejam realizadas pelo menos, uma consulta no primeiro trimestre, duas consultas no segundo trimestre e três consultas no terceiro trimestre de gestação para ser considerado um pré-natal de qualidade (Brasil, 2017).

A falha no processo de acompanhamento gestacional, tais como dificuldades o acesso, início tardio, número inadequado de consultas e realização incompleta dos procedimentos preconizados, leva a diminuição da qualidade e efetividade dessa assistência (Nunes et al. 2016; Queiroz et a. 2016; Tomasi et al. 2017; Gomes et al. 2019). Estudos demonstram que o resultado da assistência pré-natal inadequada ou inexistente acerca da mortalidade materna e neonatal pode ser decorrente da não deteç̧ão e tratamento de condições identificáveis na gravidez. O atendimento precoce e efetivo de prénatal pode desempenhar um papel importante na redução dos indicadores das principais causas de mortalidade materno fetal, além de fornecer benefícios a ambos (Brasil, 2013).

\section{Atendimento nas consultas de pré-natal: visão das gestantes}

Através dos relatos fornecidos pelas participantes da pesquisa, foi observado que a rotina das consultas médicas era precedida pelo atendimento do profissional técnico de enfermagem o qual consistia na aferição de pressão arterial e checagem do peso; após por ordem de chegada eram atendidas pelos médicos.

Ficou evidente nas falas dessas gestantes que, as atividades desenvolvidas pelos profissionais técnicos de enfermagem, ficaram restritas ao desenvolvimento de procedimentos técnicos e burocráticos não havendo envolvimento em atividades educativas durante o período da consulta de pré-natal. Entretanto a enfermagem tem papel de destaque nessas ações, que compreendem orientações sobre planejamento familiar, amamentação, cuidados com o recém-nascido e autocuidado, porém os agentes limitantes ainda abrangem um sistema de saúde deficiente em recursos físicos e humanos, compreendido pela forma tradicional de difundir as informações, de forma passiva impedindo troca de experiências e a autonomia (Silva et al. 2016).

As salas de espera pode ser uma forma produtiva de ocupar um tempo ocioso, com a transformação do período de espera em momento de aprendizado. Nesse espaço, há possibilidade de troca de experiências e saberes populares entre os usuários e profissionais de saúde, colocando em prática a educação em saúde (Queiroz et al. 2016).

Outro ponto que chamou atenção na percepção das gestantes é a demora em iniciar os atendimentos. Problemas relativos à demora na espera pelo atendimento são considerados por alguns estudos como um dos motivos de desistência do acompanhamento de pré-natal destaca-se então, a importância da pontualidade da equipe profissional envolvida nesse cuidado (Gomes et al. 2019). Os relatos a seguir demonstram a percepção das gestantes sobre a demora dos atendimentos.

Assim, eu sempre sou a primeira a ser atendida, porque minha mãe trabalha aqui, ai ela dá meu nome (E1).

Eu chego bem cedo aqui para poder ser atendida logo... Aí tem uma moça (técnica em enfermagem) que pega o nome das meninas todas e coloca na ordem, eu entro na sala e ela ver o peso, ver a pressão também, aí é só esperar eles (médicos) chamar pelo nome (E3).

Primeiro a gente dá o nome a uma mulher (técnica em enfermagem) que fica aqui na entrada, aí a gente entra nessa sala aqui ao lado e ver o peso, ver a pressão aí depois eles (médicos) chamam a gente pelo nome (E4).

Eu chego cedo sempre... Dou nome, aí elas (técnica em enfermagem) pesam né e tira a pressão e espero eles (médico) chamar (E7). 
Evidenciou-se que durante as consultas médicas, normalmente, as assistências ficaram concentradas na saúde em termos de fatores biológicos, com medição da altura do fundo uterino, ausculta de batimentos cardiofetais (BCF) e exame especular. As orientações quanto ao estado nutricional, pesquisa sobre queixas álgicas e obstétricas, questionamentos sobre medicação em uso, foram as práticas identificadas pelas participantes do estudo.

A assistência pré-natal não deve ser restrita a intervenções clínicas e obstétricas, devem ser inseridas nesse contexto as atividades de educação em saúde como práticas integrativas que visem à saúde dessas adolescentes. Embora as ações descritas nas falas estejam de acordo com as recomendações preconizadas pelo Ministério da Saúde, verificou-se uma deficiência no fornecimento de práticas educativas que estimulam a autonomia da gestante. Quando estas são aplicadas na assistência é possível ver a pessoa em sua totalidade e inserir o cuidado de forma mais especifica no seu contexto; quando ela é deficiente ou não existe afeta diretamente o vínculo com os profissionais e pacientes comprometendo o bem-estar das gestantes (Pohlmann et al. 2016).

As adolescentes não demonstraram estarem incomodadas pelo modelo assistencial dispensado a elas, não entendem a educação em saúde como parte da técnica dos profissionais que as assistem. Assim, a qualidade da assistência durante a consulta de pré-natal consiste em obter respostas aos seus questionamentos, a prescrição de exames e medicamentos.

Sabe-se que, enquanto não houver um novo modelo de assistência reconhecida pela equipe de saúde, as realizações dos atendimentos fundamentados no exame físico, na solicitação e avaliação de exames, bem como na abordagem da doença, não serão modificadas. Daí a importância desses profissionais desenvolverem práticas inovadoras voltadas para educação em saúde.

Eu gosto da consulta, eles perguntam se eu tô sentindo alguma coisa, se eu vomitei, como foi a semana, essas coisas né (E1).

Eles (médicos) são bons, eles sabem das coisas, eu tive uma coceira lá embaixo uma vez ai ele passou uma pomada, aí melhorou, ai ele falou que a menina quando tá gravida é normal ter isso, ai ele fala essas coisas que ajuda a melhorar. Aí eles (médicos) ver o tamanho da barriga, e escuta o coraçãozinho também (E2).

Escuta o coração do meu bebê. Daí se eu tiver alguma dúvida eu pergunto e eles respondem, eles pergunta se eu tenho alguma dúvida, se eu tenho alguma queixa, se eu comi direito essas coisa. Tô sim (satisfeita com a consulta), e até porque, sempre que eu tenho uma dúvida, pergunto aí eles falam (E3).

Eles (médico) fala, se eu tô sentindo alguma coisa, se eu tô tomando alguma coisa, de remédio sabe, se eu tô com dor, que eu tenho que ir pro médico se acontecer alguma coisa (E5).

Perguntou se eu tô comendo direitinho, se eu tô sentindo alguma coisa, mais alguma coisa, os remédios que estou tomando, essas coisinhas assim, e um médico veio fazer o exame (exame especular), ver se não tinha secreção (E6).

Eu gosto da consulta, assim né?! Eles (médico) perguntam sobre algumas coisas, os exames né se está tudo certinho e tal, se eu estou tendo alguma coisa, se eu sinto alguma coisa, alguma coisa fora do normal, sempre tão perguntando né (E7).

Através desses relatos, pôde-se presenciar o contexto de modelo reducionismo no atendimento do pré-natal de alto risco, observado pela percepção das gestantes. A mulher no decorrer dos anos distanciou-se do seu saber natural á medida que ficou exposta ás condutas hospitalares, assumindo posição passiva diante do seu processo de gestação e parto. Mas como 
transcender um modelo que está arraigado na vida da mulher? Uma saída deliberativa e que pode ser utilizada pela instituição é a promoção da autonomia do cuidado através da educação em saúde, uma vez que essa induz a troca de conhecimento, enriquece ideias e transforma pessoas tornando-as críticas sobre sua condição de saúde, promove relação interpessoal e abre espaço para a gestante se expressar resgatando assim o poder da tomada de decisão para esta gestante.

E ao se promover o empoderamento dessas gestantes, advindos através da educação em saúde, espera-se que essa postura em aceitar uma assistência sem qualidade seja alterada, consequente a isso que haja uma mudança dos profissionais que resistem em prestar uma assistência seguindo o modelo biomédico.

\section{Educação em saúde nas consultas de pré-natal}

Para a maioria das entrevistadas, a educação em saúde consiste nas orientações fornecidas pelos profissionais no sentido de saber se cuidar, se alimentar bem, em ter uma boa saúde, sobre os resultados de exames, ingesta hídrica e métodos contraceptivos.

As ações de educação em saúde no decorrer do pré-natal, não podem basear-se exclusivamente em transferência de informações, desconsiderando a mulher como sujeito desse processo, deve contribuir para empoderamento das gestantes no intuito de que elas exerçam seus direitos sexuais e reprodutivos de forma autônoma, e assim, façam suas escolhas e tenham cuidados visando à promoção, manutenção e recuperação do processo de gestação e nascimento de forma que elas estejam envolvidas e participem de todo o processo, bem como de maneira humanizada e qualificada (Brasil, 2005).

...é de como se cuidar? ah eles falam para eu comer bem. É isso? (E1).

Deve ser quando eles falam que é para eu comer melhor, o doutor falou para eu comer mais verdura, beterraba, essas coisas para não ter anemia, é isso! (E2).

De como se cuidar? (E3).

...deve ser quando cuida da saúde né, quando a gente come bem, e estamos bem, os exames também, eu acho que é isso? (E4).

É quando eles fala para nós beber água, comer direitinho, essas coisas (E5).

...eu acho que é sobre essas coisas, alimentação, não sei, é isso? Deve ser isso né, como evitar (métodos contraceptivos) (E7).

Sobre a participação, fora da consulta, em atividades de educação em saúde e quem foram os profissionais que participaram dessas ações; elas falaram sobre a presença na palestra de amamentação dirigida pela enfermeira como uma estratégia desenvolvida no acolhimento para início de acompanhamento de pré-natal na instituição do estudo. Os estudos apontam a predominância de palestras conferidas à prática do enfermeiro, o qual o configura como educador com características verticalizadas. Quando há o reconhecimento de tais práticas como insuficientes logo, vê-se a necessidade de ser implantado uma educação em saúde que estimule as inquietações a fim de estabelecer um raciocínio crítico sobre as condições de saúde dos educandos.

Foi sobre como amamentar, essas coisas, lembro muito não, faz tempo, foi a enfermeira que deu a aula (E1). 
Assim né, teve aquela coisa, como é o nome mesmo, palestra de amamentar, só teve essa aí num teve mais nada não, foi com a enfermeira, falou sobre como dar de mamar ao bebe. Aí ela falou sobre o parto, como cuidar do bebe, como dar banho, um monte de coisa assim (E2).

Teve quando eu entrei aqui uma palestra sobre amamentação isso conta? A enfermeira que falou de várias coisas que eu já sabia da outra gravidez, tipo assim, como amamentar, a forma certa, a posição boa para amamentar, falou de parto também, falou pouquinho mas falou quem tem normal e cesárea, falou do banco de leite, e tirou umas dúvidas de umas meninas lá que era a primeira gravidez, aí elas não sabia (E3).

Palestra de amamentação, foi numa sala e tinha mais gente como eu, foi uma enfermeira eu acho. Falou da posição de dar de mamar, que o marido não pode, como é que diz (fez o gesto de tocar no mamilo) quando tá namorando o marido não pode mexer porque pode entrar em trabalho de parto, foi bem legal, falou muita coisa, mas eu não lembro de tudo não porque faz tempo, a gente devia ter mais isso, porque tira as dúvidas, sobre cuidados com bebê, o umbigo, como limpar (E4).

Foi a enfermeira, ela que fala essas coisa com a gente, os médicos não fala nada não, sabe como os homens são né?! Assim, ela veio falando umas coisas de amamentar, aí falou de que o bebe tem que ficar no peito até 6 mês só no peito, que tem que cuidar direitinho do bebe, aí falou pra eu não deixar meu bebe mamar na outra mãe aí foi isso mesmo que ela falou (E5).

Eu assisti uma palestra da amamentação, de como o bebe nasce essas coisas, as contrações, da melhor forma de parto, tem gente que tem de cócoras, deitada, na água, tem gente que teve na água aqui? [...] foi uma coroa (enfermeira) bem legal (E6).

É mais e enfermeira, são mais vocês que dá essas orientações (E7).

Apesar de o modelo técnico assistencial ser forte, houve na unidade a aplicação de educação em saúde dentro e fora das consultas de pré-natal. Uma estratégia importante desenvolvida no ambulatório de pré-natal se deu em forma de palestra e foi oferecida pela enfermeira do setor. Nessas palestras, as elas aproveitaram para abordar diversos temas pertinentes à gestação, parto e puerpério.

A discreta adesão dos profissionais de saúde envolvidos nessa estratégia, pode ser explicada por ser um exercício diário, necessitando de persistência para se obter resultados efetivos. Entretanto, verifica-se que o enfermeiro assume essa importante função na área educativa, favorecendo a conscientização a respeito da situação vivenciada bem como a respeito das consequências advindas da escolha para a saúde dessa gestante. Observou-se isso nas falas acima quando se perguntou sobre os assuntos abordados na palestra sobre amamentação, onde as profissionais que conduziram a discussão aproveitaram o momento para promover reflexão sobre vários temas inerentes ao período gestacional e puerperal.

As adolescentes informaram que esse momento proporcionado pela instituição na qual a enfermeira promove reflexões foi bem proveitoso. As palestras consistem numa prática educativa bastante utilizada em diversos momentos e em grupos, onde são abordados vários assuntos relacionados à saúde promovendo o autocuidado. Essa estratégia favorece a interação do grupo e possibilita à gestante conhecer o seu corpo e aumenta a segurança e tranquilidade.

Cabe aos enfermeiros, que durante as consultas de pré-natal, desenvolvam atividades educativas, orientem sobre a importância do retorno as consultas a fim de prevenir e tratar alterações durante e após a gravidez (Nunes et al. 2016). Durante 
esse acompanhamento o enfermeiro tem grande destaque como educador, proporcionando a troca de informações e experiências cotidiana.

Os relatos evidenciam que, as adolescentes têm mais facilidade de falar sobre suas dúvidas e anseios com os profissionais de saúde e principalmente do sexo feminino, do que com os próprios pais. A literatura traz como motivo o receio que os pais tem em discorrer sobre métodos contraceptivos, na crença que ao se falar sobre esses assuntos estariam incitando o início precoce da vida sexual de seu filho. Falam ainda que os adolescentes muitas vezes sentem-se receosos ao buscar junto aos pais essas orientações, levando-os a buscar essas informações em meio a grupos aos quais tem mais afinidade, o que pode levar ao compartilhamento informações errôneas (Brandão et al. 2017; OPAS, 2017).

Só que dá vergonha de falar com os médicos algumas coisas aí era bom que vocês falassem com a gente que nem da outra vez (palestra realizada pela enfermeira) porque foi muito bom (E4).

Os homens não são atenciosos com a gente não, eles faz o papel dele só, mas eu prefiro tirar minha dúvidas com vocês (enfermeira) mesmo, eu acho até melhor mesmo(E5).

A gente se sentem mais confortáveis em falar com vocês (profissionais) do que com os pais em casa por que com certeza aqui é bem melhor, dá vergonha de falar com os pais e tal, as dúvidas do parto normal se vai doer, se pode fazer sexo, por que a gente não sabe, os médicos não sei se a demanda é grande que eles não dão essa atenção para a gente como vocês (enfermeiras)(E7).

Ressalta-se então, a necessidade de um olhar cuidadoso e atento pelos profissionais de saúde sobre as gestantes adolescentes, com destaque para compreensão de suas vivências e sentimentos, proporcionando o fortalecimento de sua autonomia e a responsabilização para o autocuidado de modo que possam experimentar o processo de gravidez com confiança e tranquilidade.

\section{Considerações Finais}

O presente estudo possibilitou conhecer como ocorrem as consultas médicas de pré-natal e como as gestantes adolescentes percebem a educação em saúde. Evidenciou-se que uma boa assistência de pré-natal foi associada ao ato delas terem seus questionamentos respondidos, bem como a realização de prescrição de medicamentos e solicitações de exames.

A compreensão do processo de educação em saúde esteve voltada para o repasse de informações, por meio de orientações verbais ou na forma de palestra. Essa realidade sugere a necessidade de educação permanente e capacitações para dinamizar as práticas de educação em saúde, que levem em conta as peculiaridades individuais de cada gestante, sejam elas individuais ou grupais.

Espera-se que este estudo contribua para o aprimoramento dos profissionais envolvidos na assistência do pré-natal visto que essa ferramenta é importante para os indicadores de saúde. Vale salientar, a necessidade de outras pesquisas para ampliação do conhecimento sobre educação em saúde voltada para este grupo.

\section{Referências}

Araujo, R. L. D., Rodrigues, E. S. R. C., Oliveira, G. G. \& Sousa, K. M. O. (2016). Gravidez na adolescência: consequências centralizadas para a mulher. Temas Saúde, 16(2):567-87, 2016. http://temasemsaude.com/wp-content/uploads/2016/08/16231.pdf

Bardin, L. Análise de conteúdo. (3a ed.), Edições 70. 
Brandão, E. R. \& Cabral, C. S. (2017). Da gravidez imprevista à contracepção: aportes para um debate. Cad. Saúde Pública, 33 , 2017. https://doi.org/10.1590/0102-311X00211216

Brasil. Ministério da Saúde. Secretaria de Atenção a Saúde (2017). Departamento de Ações Prográmáticas e Estratégicas. Gravidez na Adolescência no Brasil - Vozes de Meninas e de Especialistas.

Brasil. Ministério da Saúde. Secretaria de Atenção à Saúde (2018). Departamento de Ações Programáticas e Estratégicas. Proteger e cuidar da saúde de adolescentes na atenção básica.

Brasil. Ministério da Saúde. Secretaria de Atenção a Saúde (2018). Departamento de Ações Prográmáticas e Estratégicas. Taxa de gravidez adolescente no Brasil está acima da média latino-americana e caribenha.

Brasil. Ministério da Saúde. Secretaria de Atenção à Saúde (2005). Departamento de Ações Programáticas Estratégicas. Pré-natal e puerpério: atenção qualificada e humanizada.

Brasil. Ministério da Saúde. Secretaria de Atenção de Atenção à Saúde. (2013). Departamento de Atenção Básica. Atenção ao pré-natal de baixo risco.

Gomes, C. B. A., Dias, R. S., Silva, W. G. B., Pacheco, M. A. B., Sousa, F. G. M. \& Loyola, C. M. D. (2019). Consulta de Enfermagem no Pré-Natal: Narrativas de Gestantes e Enfermeiras. Texto contexto-enferm, 28, e20170544. http://www.scielo.br/scielo.php?script=sci_arttext\&pid=S010407072019000100320\&lng=pt\&nrm=iso

Habito, C. M., Vaughan, C. \& Morgan, A. (2019). Adolescent sexual initiation and pregnancy: what more can be learned through further analysis of the demographic and health surveys in the Philippines? BMC Public Health, 19: 1142, 2019. https://www.ncbi.nlm.nih.gov/pmc/articles/PMC6701073/

Leal, M. A. R. F. \& Castelar, M. (2019). Abortamento na Adolescência: Atuação de Psicólogas em Hospitais-Maternidade Públicos de Salvador, Bahia. Psicol. cienc. Prof., 39, e178707, 2019. http://www.scielo.br/scielo.php?script=sci_arttext\&pid=S1414-98932019000100108\&lng=en\&nrm=iso

Loll, D., Fleming, P. J., Manu, A., Morhe, E., Stephenson, R., King, E. J. \& Hall, K. S. (2019). Reproductive Autonomy and Modern Contraceptive Use at Last Sex Among Young Women in Ghana. International Perspectives on Sexual and Reproductive Health, 45, 1-12, https://www.jstor.org/stable/10.1363/45e7419

Matos, M. R., Condas, B. A., Cappelletti, C. \& Skupien, S. V. (2017). Atuação do profissional enfermeiro no pré-natal: educando para saúde. Revista Diálogo Educacional. https://educere.bruc.com.br/arquivo/pdf2017/24828_13151.pdf

Minayo, M. C. S. Pesquisa social: teoria, método e criatividade. Vozes, 81p.

Nunes, J. T., Gomes, K. R. O., Rodrigues, M. T. P. \& Mascarenhas, M. D. M. (2016). Qualidade da assistência pré-natal no Brasil: revisão de artigos publicados de 2005 a 2015. Cad. Saúde Colet, 24 (2): 252-261. 10.1590/1414-462X201600020171

OPAS. Organização Pan-Americana da Saúde. Ministério da Saúde. (2017). Saúde e sexualidade de adolescentes. Construindo equidade no SUS.

Pohlmann, F. C., Kerber, N. P. C., Pelzer, M. T., Dominguez, C. C., Minasi, J. M. \& Carvalho, V. F. (2016). Modelo de assistência pré-natal no extremo sul do país. Texto contexto enferm, 25(1):e3680013, 2016. http://www.scielo.br/scielo.php?script=sci_arttext\&pid=S0104-07072016000100307\&lng=pt.

Queiroz, M. V. O., Menezes, G. M. D., Silva, T. J. P., Brasil, E. G. M. \& Silva, R. M. (2016). Grupo de gestantes adolescentes: contribuições para o cuidado no pré-natal. Rev. Gaúcha Enferm, 37. http://dx.doi.org/10.1590/1983-1447.2016.esp.2016-0029

Queiroz, M. V. O. Q., Alcântara, C. M., Brasil, E. G. M. \& Silva, R. M. (2016). Participação de adolescentes em ações educativas sobre saúde sexual e contracepção. Saúde sexual e contracepção em adolescentes. Unifor, 29. https://periodicos.unifor.br/RBPS/article/view/6390

Ramos, C. F. V., Araruna, R. C., Lima, C. M. F., Santana, C. L. A. \& Tanaka, L. H. (2018). Education practices: research-action with nurses of Family Health Strategy. Rev Bras Enferm, 71(3):1144-51, 2018. http://www.scielo.br/pdf/reben/v71n3/pt_0034-7167-reben-71-03-1144.pdf

Rodrigues, A. R. S., Barros, W. M. \& Soares, P. D. F. L. (2016). Reincidência da gravidez na adolescência: percepções das adolescentes. Enfermagem em Foco, 7 (3/4): 66-70, 2016. http://revista.cofen.gov.br/index.php/enfermagem/article/view/945

Rosa, C. (2018). Vidas perdidas: análise descritiva do perfil da mortalidade dos adolescentes no Brasil. Adolesc. Saude, 15(2), 29-38. http://adolescenciaesaude.com/detalhe_artigo.asp?id=716

Santos, E. S., Conceição, I. M. \& Moura, P. A. (2017). Gravidez e abandono escolar de adolescentes negras: qual o papel da escola nesse contexto? Encontro Internacional de Formação de Professores e Fórum Permanente de Inovação Educacional, 10(1). https://eventos.set.edu.br/index.php/enfope/article/view/5268

Silva, C. S., Souza, K. V., Alves, V. H., Cabrita, B. A. C. \& Silva, L. R. (2016). Atuação do enfermeiro na consulta pré-natal: limites e potencialidades. Rev Fund Care, 8(2):4087-4098, 2016. http://dx.doi.org/10.9789/2175-5361.2016.

SINASC. Sistema de Informações de Nascidos Vivos. 2018.

Tomasi, E., Fernandes, P. A. A., Fischer, T., Siqueira, F. C. V., Silveira, D. S., Thumé, E., Duro, S. M. S., Saes, M. O., Nunes, B. P., Fassa, A. G. \& Facchini, L. A. (2017). Qualidade da atenção pré-natal na rede básica de saúde do Brasil: indicadores e desigualdades sociais. Cad. Saúde Pública, 33. https://doi.org/10.1590/0102-311X00195815

UNFPA. Acelerar el progreso hacia la reducción del embarazo en la adolescencia en América Latina y el Caribe. Informe de consulta técnica. EE. UU, https://lac.unfpa.org/sites/default/files/pub-pdf/ESP-EMBARAZO-ADOLES-14febrero\%20FINAL_5.PDF 